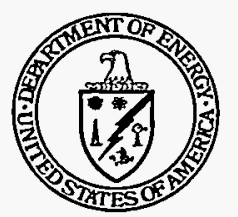

\title{
PCB Spill Response and Notification Requirements
}

BACKGROUND:

\begin{abstract}
Polychlorinated biphenyls (PCBs) are a class of organic chemicals that had become widely used in industrial applications due to their practical physical and chemical properties. Historical uses of PCBs include dielectric fluids (used in utility transformers, capacitors, etc.), hydraulic fluids, and other applications requiring stable, fire-retardant materials. Due to findings that PCBs may cause adverse health effects and due to their persistence and accumulation in the environment, the Toxic Substances Control Act (TSCA), enacted on October 11, 1976, banned the manufacture of PCBs after 1978 [Section 6(e)]. The first PCB regulations, promulgated at 40 CFR Part 761 , were finalized on February 17, 1978. These PCB regulations include requirements specifying disposal methods and marking (labeling) procedures, and controlling PCB use. To assist the Department of Energy (DOE) in its efforts to comply with the TSCA statute and implementing regulations, the Office of Environmental Guidance has prepared the document "Guidance on the Management of Polychlorinated Biphenyls (PCBs)." That document explains the requirements specified in the statute and regulations for managing PCBs including PCB use, storage, transport, and disposal.
\end{abstract}

The Environmental Protection Agency (EPA) established regulations at 40 CFR 761 Subpart G for the reporting and cleanup of spills resulting from the release of any quantity of material containing PCBs at concentrations of $\geq 50 \mathrm{ppm}$. The regulations, known collectively as the TSCA Spill Cleanup Policy, contain requirements for the notification, cleanup, decontamination verification, and recordkeeping of PCB spills. This Information Brief supplements the PCB guidance document by responding to common questions concerning PCB spill response and notification requirements. It is one of a series of Information Briefs pertinent to PCB management issues.

STATUTE: $\quad$ Toxic Substances Control Act of 1976 (TSCA)

REGULATION: $\quad 40$ CFR Part 761

REFERENCES: 1. "Guidance on the Management of Polychlorinated Biphenyls (PCBs)," Environmental Guidance Manual, DOE Office of Environmental Guidance, RCRA/CERCLA Division (EH-231), DOE/EH-0350, June 1993.

2. "PCB Spill Cleanup Policy," Final Rule, U.S. Environmental Protection Agency, 52 FR 10688, April 2, 1987.

3. "Hazardous Substances Release Reporting under CERCLA, EPCRA Section 304 and DOE Emergency Management System/Occurrence Reporting Requirements," EH-231 Guidance Document, DOE Office of Environmental Guidance (EH-231), DOE/EH-0383, June 1994.

4. "Disposal Requirements for PCB Waste," EH-231 TSCA Information Brief, EH-231-056/1294, Office of Environmental Guidance, RCRA/CERCLA Division, December 1994.

5. "PCBs and Electrical Transformers," Final Rule, Environmental Protection Agency, 50 FR 29170, July 17, 1985.

\section{What constitutes a PCB spill?}

According to the TSCA regulations, "spills" can be defined as intentional and unintentional spills, leaks, and other uncontrolled discharges of PCBs where the release results in any quantity of PCBs running off or about to run off the external surface of equipment or other sources of PCBs, as well as the contamination resulting from a spill. In practice, a leak becomes a PCB spill when the leak of PCBs is running off or about to run off the external surface of the PCB source (e.g., a transformer). This subtle distinction determines whether the TSCA PCB Spill Cleanup Policy [40 CFR 761 Subpart G] applies. Regardless, the TSCA regulations consider leaking equipment to be an unauthorized use; facility managers should repair or remove and dispose of the faulty equipment.

What authorities should be contacted in case of a spill or leak of PCBs, and when?
As soon as the person in charge of a facility or vessel has knowledge of a release of ${ }^{3} 1$ pound of PCBs by weight over a 24hour period, the spill must be reported to the National Response Center at 1-800-424-8802. Furthermore, the responsible party must notify the EPA Regional Office, Pesticide and Toxic Substances Branch, of spills of $>10$ pounds $P C B$ by weight in the shortest possible time after discovery, but in no case later than 24 hours after discovery.

If a spill results in PCB exposure to persons outside the facility, the spill must be reported to (1) the community coordinator for the Local Emergency Planning Committee (LEPC) of any area likely to be affected by the release and (2) the State Emergency Response Commission (SERC) of any State likely to be affected. In cases where there is no LEPC, the relevant local emergency response personnel (e.g., the fire department) must be contacted. Notification is not required for spills of $<1$ pound of PCBs or spills of $<270$ gallons of untested mineral oil. 
If any $\mathrm{PCB}$ transformer containing PCBs at a concentration of $\geq 500 \mathrm{ppm}$ is involved in a fire-related incident, the owner of the transformer must notify the National Response Center immediately. The owner must disclose information about the cause of the firerelated incident and the type of transformer installation.

\section{How soon must cleanup efforts begin and what are the required response actions?}

Cleanup efforts must begin within 24 hours after the discovery of a spill of any amount of high-concentration PCBs ( $\geq 500 \mathrm{ppm}$ ) and spills of $\geq 1$ pound of low-concentration PCBs ( $\geq 50 \mathrm{ppm}$ but $<500 \mathrm{ppm}$ ) or 270 gallons or more of untested mineral oil. Within 24 hours after discovery of a high-concentration spill or a lowconcentration spill of PCBs as specified above, the responsible party must do the following: (1) delineate and restrict access to the area that encompasses any visible traces of the spill plus a three-foot buffer,(2) place clearly visible signs advising people to avoid the area, (3) record and document the area of visible contamination, (4) clean up all visible traces of the fluid on hard surfaces, and (5) initiate removal of all visible traces of the spill on soil and other media. If there are no visible traces of the spill, within 24 hours the responsible party must perform the following actions: (1) document the fact that there are no visible traces of the spill, (2) estimate the area of the spill (based on the amount of material missing from the equipment or container), (3) immediately cordon off the area of suspected contamination, and (4) identify the spill boundaries using a statistically-based sampling scheme. For spills that contaminate water resources or sewers, the facility must contact the appropriate EPA Regional Office within 24 hours of the discovery of a spill to obtain guidance on cleanup criteria. Measures to minimize the impact of spills contaminating grazing lands or gardens also must be initiated immediately upon discovery of the spill.

Within 48 hours of the discovery of a spill of $<1$ pound of PCBs with a concentration $<500 \mathrm{ppm}$, the facility must perform the following actions: (1) double-wash/rinse any affected solid surfaces, as described at 40 CFR 761.3; (2) clean to a concentration of $\leq 10$ micrograms per 100 square centimeters any indoor surfaces (except in vault areas); and (3) if the spill occurs onto soil, excavate all soil in the spill area and restore the ground to its original condition.

\section{What if immediate spill cleanup is impossible?}

Emergency or adverse weather conditions may prevent immediate spill cleanup measures from being conducted. The causes of any delays must be documented in the facility records. The occurrence of a spill on a weekend or holiday or outside regular working hours will not be accepted by regulatory authorities as a valid reason for a delay in responding to a spill; facilities should have spill response procedures in place that will be implemented if a spill of PCBs occurs during non-work hours.

\section{What are the cleanup requirements for a recent spill of PCBs?}

Requirements for remediating recent spills (i.e., after April 2, 1987) are discussed in the TSCA Spill Cleanup Policy. The policy sets decontamination requirements that apply to all high-concentration spills ( $\geq 500 \mathrm{ppm}$ ) and low concentration spills ( $\geq 50 \mathrm{ppm}$ but $<500 \mathrm{ppm}$ ) of $\geq 1$ pound of PCBs or $\geq 270$ gallons of untested mineral oil.
Spills that occur in outdoor electrical substations must be decontaminated to a concentration of $\leq 100$ micrograms per 100 square centimeters for solid surfaces. Contaminated soil must be cleaned to a concentration of $\leq 25 \mathrm{ppm}$ (i.e., soil must be excavated so that any residual remaining is $25 \mathrm{ppm}$ PCB or less). Alternatively, contaminated soil may be cleaned to a concentration of $\leq 50 \mathrm{ppm}$ provided that a label or notice is visibly placed in the area.

Spills that occur in restricted-access locations (i.e., areas located $>0.1$ kilometers from a residential or commercial area and where accessibility is limited by manmade or natural barriers) must be cleaned to a concentration of $\leq 10$ micrograms per 100 square centimeters for all solid surfaces. Contaminated soil must be excavated to a level of $25 \mathrm{ppm}$ PCB or less.

$\square$ Spills that occur in non-restricted access locations (residential and commercial areas such as indoor locations and unrestricted rural areas) must also be decontaminated to a concentration of $\leq 10$ micrograms per 100 square centimeters for all solid surfaces. Contaminated soil must be cleaned to a level of $\leq 10 \mathrm{ppm}$ PCB provided that the soil has been excavated to a depth of at least 10 inches and the soil has been replaced with clean fill containing $<1$ ppm PCB.

DOE personnel should consult with the appropriate EPA Regional Office for suggestions on a type of cleaner or solvent to use for decontamination. If decontamination to a concentration of $\leq 10$ micrograms per 100 square centimeters is not possible, then encapsulation is permitted for treatment of low-contact, indoor, "nonimpervious" surfaces provided that the surface had been decontaminated to a concentration of $\leq 100$ micrograms per 100 square centimeters. However, EPA may decide not to allow the encapsulation option for a particular spill if failure of the encapsulation could create an imminent hazard at the site. All replaceable household items, which would include items such as contaminated office furnishings, must be disposed of as PCB waste.

If a spill will result in potential PCB exposure to persons outside the boundary of the facility or involve contamination of surface water or ground water, the spill is generally addressed on a case-by-case basis at the EPA Regional level.

\section{What are the requirements for cleaning up spills that pre-date the TSCA Spill Cleanup Policy?}

Any spills that occurred before the effective date of the TSCA Spill Cleanup Policy (i.e., before May 4, 1987) and spills where the date or original quantity and PCB concentration of the spill is unknown must be remediated according to requirements determined by the appropriate EPA Regional Office on a site-specific basis. However, PCB materials that were disposed of in a land disposal unit (e.g., landfill) prior to the existence of the PCB disposal regulations (i.e., prior to February 17, 1978) are considered by EPA to be "in service," and are not required to be removed from the land disposal unit, provided that no PCBs are migrating from the site. If these PCB materials are removed from a land disposal unit, however, they lose their "in service" status and must then be disposed of in accordance with the TSCA PCB disposal 


\section{DISCLAIMER}

This report was prepared as an account of work sponsored by an agency of the United States Government. Neither the United States Government nor any agency thereof, nor any of their employees, make any warranty, express or implied, or assumes any legal liability or responsibility for the accuracy, completeness, or usefulness of any information, apparatus, product, or process disclosed, or represents that its use would not infringe privately owned rights. Reference herein to any specific commercial product, process, or service by trade name, trademark, manufacturer, or otherwise does not necessarily constitute or imply its endorsement, recommendation, or favoring by the United States Government or any agency thereof. The views and opinions of authors expressed herein do not necessarily state or reflect those of the United States Government or any agency thereof. 


\section{DISCLAIMER}

Portions of this document may be illegible in electronic image products. Images are produced from the best available original document. 
regulations at $40 \mathrm{CFR} 761.60$. Although PCBs disposed of prior to February 17, 1978, are not required to be removed from the site and disposed of according to the regulations at 40 CFR 761.60, they can still be addressed under provisions of the Comprehensive Environmental Response, Compensation, and Liability Act (CERCLA).

\section{How can DOE demonstrate that a spill cleanup meets the TSCA requirements?}

Post-cleanup sampling is required by $40 \mathrm{CFR} 761.130$ to verify the level of cleanup. Facilities must keep records to confirm that sampling was conducted and to document the results of that testing. EPA recommends the use of a sampling scheme developed by the Midwest Research Institute (MRI), which is available through the EPA TSCA Assistance Office (contact the TSCA hotline at (202) 554-1404). In addition, EPA may take samples from any spill site to verify cleanup. In general, when the procedural and numerical requirements specified in the PCB Spill Cleanup Policy are met, EPA will consider the spill to have been cleaned up. However, if EPA decides that cleanup levels have not been achieved, based on a review of cleanup records or post-cleanup sampling undertaken by EPA, the agency has reserved the right to require further cleanup.

\section{What other factors could affect PCB spill cleanup?}

Two important factors to be considered are (1) whether the PCBs are contaminated with radioactive materials or with $\mathrm{Re}$ source Conservation and Recovery Act (RCRA) hazardous wastes and (2) whether the spill is part of a larger CERCLA remedial action or RCRA corrective action. PCB spills that involve wastes regulated by statutes other than TSCA must be managed so that the most stringent cleanup requirements are met. For example, solid wastes containing RCRA hazardous components and regulated PCBs must be disposed of at a TSCA-approved facility that is also in possession of a RCRA permit. Spills occurring prior to May 4, 1987, (as would likely be the case in a CERCLA remedial action) do not fall under the PCB Spill Cleanup Policy and the EPA Regional Office would specify or approve cleanup requirements through the appropriate cleanup decision document (e.g., CERCLA Record of Decision or RCRA Statement of Basis/Response to Comments). DOE should also rely on EPA Regional discretion when addressing PCB spills that are part of a larger environmental restoration effort or if the original concentration of PCBs in the material that was spilled is unknown.

\section{How should the PCB concentration be determined for soils and other materials that have become contaminated as the result of a spill or leak?}

All spilled materials with a PCB concentration of $50 \mathrm{ppm}$ or greater and most materials contaminated with $\mathrm{PCBs}$ as a result of a spill are "wastes" and must be disposed of pursuant to the TSCA regulations at $40 \mathrm{CFR} 761.60$. In accordance with the Anti-dilution Rule [40 CFR 761.1(b)], the concentration of PCBs in materials that have been contaminated with PCBs as a result of a spill (e.g., soil) must be considered to have the same concentration as the material that was spilled, regardless of the actual concentration of PCBs in the contaminated material. The
Anti-dilution Rule specifies that any PCB material that has been intentionally or unintentionally diluted is considered to have the original concentration of PCBs for the purposes of the TSCA regulations. (Please see reference \#4.)

\section{Can any assumptions be made about the PCB concentration of spilled material if the actual concentration is unknown?}

Yes. TSCA regulations do allow certain assumptions to be made about the PCB concentration of spilled material if the actual concentration is unknown. For example, fluids of unknown PCB concentration released as the result of a transformer rupture must be assumed to have a PCB concentration of $\geq 500 \mathrm{ppm}$ if the transformer's nameplate indicates that the transformer contains PCB dielectric fluid or if dielectric fluid with a PCB concentration of $\geq 500 \mathrm{ppm}$ is known or suspected to have been added to the transformer. PCB transformers are also assumed to contain PCB concentrations of $\geq 500 \mathrm{ppm}$ if the transformer does not have a nameplate and there is no information available to indicate the type of dielectric fluid it contains. If a spill or rupture involving a transformer originally containing mineral oil occurs, the transformer must be assumed to contain PCBs at a concentration of at least $50 \mathrm{ppm}$ unless a subsequent test or other information indicates otherwise.

Are there any special requirements for spill cleanup or notification when a transformer ruptures?

Yes. Any incident that generates sufficient heat and/or pressure to result in the violent or non-violent rupture of a PCB transformer (i.e., $\geq 500 \mathrm{ppm}$ PCB) or the release of PCBs from such a transformer is considered a fire-related incident and is subject to special requirements described in the "Fires Rule" [50 FR 29170]. Firerelated incidents must be reported immediately to the National Response Center. Information on the cause of the incident and the type of transformer installation should be included in the report. Special measures intended to mitigate the effects of the incident are required, such as containment and treatment of any water used in cleanup or fire-control operations. Ruptures of transformers containing PCBs at a concentration of $<500$ ppm are not considered "firerelated incidents" and, as a result, are not subject to the special requirements of the Fires Rule.

\footnotetext{
Questions of policy or questions requiring policy decisions will not be addressed in EH-231 Information Briefs unless that policy has already been established through appropriate documentation. Please refer any questions concerning the subject material covered in this Information Brief to Carolyn Thompson Walder, RCRA CERCLA Division, EH-231, (202) 5868248.
} 
Post Office, if unable to deliver please return to:

Gabrielle Santore

Environmental Compliance Group

Building 800 TPK, MS-6482

Oak Ridge National Laboratory

Oak Ridge, TN 37831-6482

ADDRESS CORRECTION REQUESTED 